\title{
Evaluating capacitive deionization for water desalination by direct determination of chloride ions
}

P. Díaz, Z. González, M. Granda, R. Menéndez, R. Santamaría*, C. Blanco

Instituto Nacional Del Carbón, INCAR-CSIC, Apdo. 73, 33080 Oviedo, Spain

\begin{abstract}
Ionic conductivity and capacitance measurements are widely used methods for evaluating the desalination efficiency in capacity deionization processes. In this study, these methods are revised and several problems associated to them identified and evaluated. Furthermore, a new method based on the determination of the chloride ion concentration by means of a chloride selective electrode is proposed as a more reliable alternative for evaluating the desalination performance in these systems. This method has been shown not only to be precise in a wide range of salt concentrations but also to be independent of $\mathrm{pH}$, one of the main limitations of the determinations based on ionic conductivity measurements.
\end{abstract}

Keywords: desalination, capacitive deionization, ionic conductivity, capacitance, chloride selective electrode.

\section{Introduction}

In recent years the increase of the world population, the overexploitation of natural resources, industrial development and pollution have given rise to a serious water scarcity problem [1]. Moreover, climate change and the increasing desertification of large areas of land have turned water into a luxury product [2]. In this context the desalination (or salt removal) of sea water or brackish water has emerged as an important alternative to deal with the problem of water

\footnotetext{
* Corresponding Author: Fax (+34) 9852976 62. E-mail address: riqui@incar.csic.es (R. Santamaría)
} 
shortage. Although several methods such as reverse osmosis, electro-dialysis and distillation are commonly used for salt removal, capacitive deionization technology (CDI) has attracted interest recently as a promising and more energy efficient procedure [3].

CDI is an electrochemically controlled method for removing salt from aqueous solutions [4]. It takes advantage of the ions adsorbed into the electrical double layer region at the electrodesolution interface when the electrode is electrically charged by an external power supply. During this step (polarization), the anions are electroadsorbed into the anode (electrode of positive polarity) and the cations into the cathode (electrode of negative polarity), as a result of which the concentration of ions in the initial saline/salty solution is reduced. Then, in the depolarization step, the cell voltage is reduced, reversed or shorted and the previously stored ions are released into a waste water solution (Figure 1). The configuration of these devices, which is similar to that of electrochemical double layer capacitors, allows the energy from the depolarization step to be used in the next polarization cycle. As a result, the overall process of desalination is less expensive in terms of energy consumption [5].

Most of the research in this field has been focused on the search for electrode materials with suitable properties, such as high specific surface area, good chemical stability, suitable pore size distribution, high electrical conductivity and good wettability [6]. In this context, the performance of several carbon materials, such as activated carbons [7], aerogels [8], nanotubes [9], fibers [10], ordered porous materials from templates [4] and most recently graphene and their composites [11,12] has been investigated. Of these, activated carbons (ACs) seem to be the most promising for use as CDI electrode materials, mainly due to their high specific surface area, low cost and easy scalability [5].

Despite of the increasing interest in desalination by means of CDI, the methods used for evaluating the desalination efficiency need to be revised. The most widely used method to 
estimate ion retention capability is based on ionic conductivity $(\sigma)$ measurements of the treated water [13-16], which allows the progress of the CDI experiment to be continuously controlled. A linear relationship between the ionic conductivity measured and the concentration of salty ions in the corresponding solution is assumed, and the desalination efficiency $(R)$ is calculated from the difference between ionic conductivity before and after the polarization step. However, the $\sigma$ values and, consequently, the desalination performance evaluation can be influenced by variations in $\mathrm{pH}$ of the solution, which are commonly observed during the polarization/depolarization steps [17-19].

Capacitance values are also widely used to estimate the salt retention capability of different samples, the capacitances measured being assigned to the double layer formation and that, to the ion retention capability of the material under study $[9,15,20]$. But, contrary to what occurs when using the conductivity method, the capacitance values do not correspond to measurements performed directly on the treated water but to indirect measurements that may not be directly related to the salt retention capability of the sample.

In the present study, these widely used methods for the evaluation of the desalination efficiency of a CDI device with activated carbons as active electrode materials (capacitance and conductivity measurements), are investigated and the problems associated with them are discussed. Furthermore, a new method based on the determination of the chloride ion concentration by means of a chloride selective electrode (CSE) is proposed as a more reliable alternative for evaluating the desalination performance in these systems. 


\section{Material and methods}

\subsection{Active electrode materials}

Two activated carbons, $A$ and $N$, were selected as active materials for the fabrication of the CDI electrodes. Both of them were previously tested as electrode materials for supercapacitors and their ability to form the electrical double layer had been demonstrated [21]. $A$ was obtained in our lab by chemical activation of a mesophase pitch with $\mathrm{KOH}$ [22]. $N$ (Norit DLC Super 50 Nederland BV) is a commercial activated carbon obtained by physical activation of natural precursors with steam. Both samples were characterized in terms of their textural properties (pore volume, BET surface area, microporous surface area, and microporous volume) and oxygen content (elemental analysis) [21].

\subsection{Electrode preparation and laboratory bench-scale CDI unit}

Two carbon pastes $(A P$ and $N P$ ) were initially prepared in an agate mortar by thoroughly mixing optimized amounts of the activated carbons ( $1 \mathrm{~g}$ of $A$ or $N$, respectively), polyvinylidene fluoride (PVDF, Sigma Aldrich) as binder ( $5 \%$ for $A$ and 10\% for $N$ ) and dimethylacetamide (DMAC, Sigma Aldrich) as solvent (5-8 mL). The textural properties of the pastes were also determined following the same procedures as for the activated carbons.

Films of the as-prepared pastes were deposited by tape casting [23] on one side of square graphite plates (Schunk Ibérica, SA) which would then act as current collectors. The resulting electrodes $(A P$ and $N P)$ had a thickness of $200 \mu \mathrm{m}$, a geometric surface area of $100 \mathrm{~cm}^{2}$ and an average active material content of 0.35 and $0.30 \mathrm{~g}$ respectively (depending on the corresponding paste composition). Finally, the electrodes were dried in a vacuum oven at $40^{\circ} \mathrm{C}$ to remove any excess of solvent. Prior to their use in the experiments, all the electrodes were immersed in a $0.1 \mathrm{M} \mathrm{NaCl}$ solution, for at least $24 \mathrm{~h}$, for equilibrium to be reached after physical adsorption of the salty ions [24]. 
The experiments were carried out in a flow-by device (Figure 2) in single-pass mode [25]. Pairs of each of the two types of electrodes were placed facing each other in a methacrylate homemade cell, leaving a $1 \mathrm{~mm}$ gap between them. A fixed volume $(14 \mathrm{~mL})$ of a $0.1 \mathrm{M}\left(\sim 5850 \mathrm{mg} \mathrm{L}^{-}\right.$ $\left.{ }^{1}, \sigma=10.75 \mathrm{mS} \mathrm{cm}^{-1}, \mathrm{pH}=5.62\right) \mathrm{NaCl}$ solution (Sigma Aldrich) was used both as feed (to be desalted) and waste water (in which the depolarization step takes place). The solution was pumped into/out of the device following a stop-flow circulation mode by means of a peristaltic pump.

The different electrochemical studies were performed by coupling the CDI unit to an external power supply (DC current, Biologic VMP Multichannel Potentiostat).

\subsection{Capacitance measurements}

The desalination efficiencies were estimated first from the capacitance values. Capacitance measurements were performed in the CDI unit operating in static mode $(14 \mathrm{~mL}$ of $\mathrm{NaCl}$ solution). Galvanostatic charge/discharge tests were carried out by applying a constant current density of $0.25 \mathrm{mAcm}^{-2}$ in a voltage range of $0.0-1.2 \mathrm{~V}$. The cell capacitance $(C)$ was calculated from the discharge voltage profile by means of Equation (1) [26].

$$
C(\mathrm{~F})=I \Delta t / \Delta V
$$

where $I$ is the discharge current (A), $\Delta t$ is the discharge time (s) and $\Delta V$ is the voltage difference (V) omitting the ohmic drop (See Supplementary data for electrode capacitance values).

From the $C$ values, the theoretical desalination efficiencies of the corresponding CDI devices $\left(R_{c}\right.$, Table 2$)$ were calculated by applying Equation (2)

$$
R_{c}=C V M_{w} / F m_{t}
$$

where $V$ is the cell voltage applied (V), $M_{w}$ is the molecular weight of $\mathrm{NaCl}\left(58.489 \mathrm{~g} \mathrm{~mol}^{-1}\right), F$ is Faraday's constant $\left(96.485 \mathrm{C} \mathrm{mol}^{-1}\right)$ and $m_{t}$ is the total weight of the active material in the two electrodes which make up the device (without the binder). 


\subsection{Desalination experiments}

The salt-removal experiments were carried out in a two-step chronoamperometric procedure. As the first step (polarization) a voltage $(\Delta V)$ of $1.2 \mathrm{~V}$ was applied for 1 min between the two electrodes in order to electroadsorb the salty ions from the feed water introduced into the cell. Then, the treated water was removed and replaced by the same volume of a fresh $0.1 \mathrm{M} \mathrm{NaCl}$ solution (waste water) while maintaining the polarization of the electrodes. Finally, in the second step (depolarization), the two electrodes were shorted (10 min) by putting them into electrical contact to desorb the previously removed ions.

Prior to the evaluation of the desalination efficiency of both types of CDI electrodes (AP and $N P), 10$ polarization/depolarization cycles were performed in the corresponding device to ensure that they had reached dynamic equilibrium [25].

\subsection{Evaluation of desalination efficiency}

The desalination efficiency $(R)$ of the CDI electrodes under study was evaluated from the differences in concentration between the initial salty solutions and the treated water samples by means of Equation (3)

$$
R=\left[\left(X_{0}-X\right) M_{w} v\right] / m_{t}
$$

where $X_{0}$ and $X$ are the initial and final $\mathrm{NaCl}$ concentrations respectively ( $\left.\mathrm{mol} \mathrm{L}^{-1}\right), M_{w}$ is the molecular weight of $\mathrm{NaCl}\left(58.485 \mathrm{~g} \mathrm{~mol}^{-1}\right), v$ is the volume of the water solution introduced into the CDI device $(0.014 \mathrm{~L})$ and $m_{t}$ is the total mass of active material in the device. $X_{0}$ and $X$ were calculated from either the ionic conductivity of the solutions $(\sigma)$ or the chloride ions concentration $\left(\mathrm{Cl}^{-}\right)$, as described in the next sections, to yield $\left(R_{\sigma}\right)$ or $\left(R_{C l}{ }^{-}\right)$, respectively. 


\subsubsection{Ionic conductivity measurements}

The $\sigma$ values of the solutions were directly measured using a conductivity sensor (InLab 730, Mettler-Toledo) coupled to a conductimeter (Seven Multi, Metter Toledo). The results obtained were related to the $\mathrm{NaCl}$ concentrations $\left(X_{\mathrm{NaCl}}\right)$ by means of a calibration curve (See Figure $\mathrm{S} 1$, Supplementary data).

\subsubsection{Chloride-ion concentration measurements}

The $\mathrm{Cl}^{-}$concentration was measured using an ion selective electrode (PerfectIon $\mathrm{Cl}^{-}$, Metter Toledo) which responds to the ionic activity of the chloride ions, i.e., it measures the number of effective ions in solution [27]. The directly measured electrode potential, $E(\mathrm{~V})$, is related to the activity of the ionic species by the Nernst equation (Eq. 4).

$$
E=E^{0}+2.3(R T / n F) \log a
$$

where, $E^{0}$ is a constant, $R$ is the gas constant $\left(\mathrm{J} \mathrm{K}^{-1} \mathrm{~mol}^{-1}\right), T$ is the temperature $(\mathrm{K}), n$ is the number of moles of electrons transferred in the balanced equation,,$F$ is the Faraday constant (C $\mathrm{mol}^{-1}$ ) and $a$ is the ionic activity. As the ionic activity and the ionic concentration can differ in concentrated solutions such as those used in our experiments [28], direct determination of the $\mathrm{Cl}^{-}$ concentration was not possible. Therefore, an incremental method was selected and optimized for this study. Particularly, the determination of the $\mathrm{Cl}^{-}$concentration was performed by a sample-addition method [29-30]. This determination does not require a previous calibration step but only the verification of the correct electrode operation. For this purpose, the slope of the CSE (S), which is defined as the change in millivolts observed with every tenfold change in the $\mathrm{Cl}^{-}$concentration, was measured. Thus, $1 \mathrm{~mL}$ of a $0.1 \mathrm{M} \mathrm{NaCl}$ standard solution and $2 \mathrm{~mL}$ of ionic strength adjusting buffer (ISAB) was added to $100 \mathrm{~mL}$ of distilled water and the corresponding potential value $\left(E_{0}\right)$ was determined. Then, $10 \mathrm{~mL}$ of the same $\mathrm{NaCl}$ standard solution was added and the potential was measured again $\left(E_{f}\right)$. The difference between the two 
potential values measured is related to the slope of the electrode, which needs to be in the range of 54-60 mV/magnitude order.

To determine chloride ion concentration in either the feed or treated water, first the $\mathrm{Cl}^{-}$selective electrode was immersed in a known volume of a $\mathrm{NaCl}$ standard solution, whose ionic strength and $\mathrm{pH}$ were adjusted by the addition of a saturated $\mathrm{NaNO}_{3}$ solution (PerfectION ${ }^{\mathrm{TM}}$, ISA Solid State, Mettler Toledo) as ISAB. Then, an aliquot of the tested sample was added. The $\mathrm{Cl}^{-}$ concentration was determined from the changes in the potential values measured before and after the addition, by means of Equation (5) [31].

$$
X=X_{s t}\left(v^{\prime} / v\right)\left\{10^{\Delta E / S}-\left(v_{s t} / v^{\prime}\right)\right\}
$$

where $X$ is the chloride concentration in the sample tested, $X_{s t}$ is the chloride concentration of the standard solution, $v$ is the volume of the tested sample, $v_{s t}$ is the volume of the standard solution, $v^{\prime}$ is the final volume $\left(v+v_{s t}\right), \Delta E$ is the potential difference and $S$ is the slope of the electrode.

\subsection{3. $\mathrm{pH}$ measurements}

The $\mathrm{pH}$ of all the solutions was also determined by means of a pH meter (Seven Easy, MettlerToledo).

\subsection{Validation of the methodology proposed}

As mentioned above, the determination of $\mathrm{Cl}^{-}$concentration using the incremental method described previously does not require calibration. In this particular case, the concentration range in which the method can be reliably applied depends exclusively on the concentration of the standard solution used during the determination. That is to say, when a $0.01 \mathrm{M} \mathrm{NaCl}$ standard solution is used the samples need to be in the range of $0.05 \mathrm{M}-5.0 \mathrm{M}$, while for a $0.001 \mathrm{M} \mathrm{NaCl}$ standard solution the concentration interval is $0.005-0.05 \mathrm{M}$. In this way, the operational range can be quickly adapted by selecting an adequate $\mathrm{NaCl}$ standard solution. 
Furthermore, the $\mathrm{NaCl}$ concentration of the standard solutions used in the elaboration of the calibration curve for the ionic conductivity measurements was also determined for purposes of comparison (See Figure S2, Supplementary data).

To evaluate the preciseness of this method, $\mathrm{NaCl}$ solutions of different concentrations $(0.005-$ $0.5 \mathrm{M})$ were prepared. Five measurements were performed for each solution.

Finally, the influence of changes in the $\mathrm{pH}$ values on the measurements was evaluated. For this purpose, several $0.1 \mathrm{M} \mathrm{NaCl}$ solutions with different $\mathrm{pH}$ values (by the addition of small volumes of $\mathrm{NaOH}$ or $\mathrm{HCl}$ solutions) were prepared. It is important to remark that the volume of the basic or acid solutions added to change the $\mathrm{pH}$ values was small enough to ensure that that the ionic strength of the solutions remained constant. The samples were evaluated from both the conductivity and chloride concentration measurements to identify the most reliable method of evaluating desalination performance.

\section{Results and discussion}

\subsection{Characterization of active electrode materials}

The activated carbons used as active electrode materials, $A$ and $N$, have different textural characteristics (Table 1). Although both of them are mainly microporous carbons, in $A$ the total pore volume and the BET surface area are significantly higher, as is the oxygen content. After the preparation of the corresponding pastes for the electrodes, the textural differences were maintained, both of them showing a significant reduction in their microporous volume and, consequently, in their BET surface area [32]. In the view of the textural characteristics of the electrode pastes, it was expected that they would behave rather differently when used for the retention of ions from salty solutions. 


\subsection{Evaluation of the desalination efficiency}

The desalination efficiency of the electrodes under study was evaluated using the three different methods described in the experimental section: capacitance, ionic conductivity and chloride ion concentration measurements. The values of salt retention capability obtained by each method are presented in Table 2, with significant discrepancies between them. It is important to remark that, in the case of the capacitance measurements, the experiments were performed in static mode, in which the salty water was not removed from the CDI device (see Section 2.3). In the other two cases, the measurements were performed on the solution extracted from the device during the desalination experiments.

As stated in the introduction, many authors have used the ability of a carbon to form the electrical double layer in a capacitor as an indication of the performance of this carbon in a CDI process $[7,9,15]$, by correlating the specific capacitance of the electrodes with the amount of salt retained [20]. Table 2 shows the cell capacitances for the electrodes prepared with both materials. As expected in the view of their textural differences, $A P$ has a significantly higher capacitance than $N P$ (15 vs $9 \mathrm{~F}$, respectively). The values of capacitance can be easily transformed into salt retention by simply applying the Faraday law (see experimental section). This yielded retention values of $31 \mathrm{mg}$ of salt per gram for carbon $A$ and $21 \mathrm{mg} / \mathrm{g}$ for carbon $N$.

Nonetheless, there are several considerations that need to be taken into account. The first one is the different methodology of the capacitance measurement with respect to desalination process. As stated before, the first one was a static method where no measurements were performed on the treated water, while in the desalinization experiments measurements were performed directly on the treated water removed from the device.

Furthermore, the retention capabilities were estimated assuming that the capacitance measured corresponds to the double layer formation, with ions moving from the bulk of the solution to the 
opposite charged electrode interface. However, in reality the system is more complex. It is not necessary that the electrolyte ions to migrate long distances in order to form the double layer. Activated carbons are adsorbent materials, with a high ability to adsorb different substances onto their large surfaces. When a salt solution is put into contact with an activated carbon, ions are unspecifically adsorbed (without the need for polarization) into the porous network of the carbon. When the electrodes are polarized the ions form the double layer, but many of the ions forming this double layer are already in the pores and the exchange with the solution in between the electrodes is limited. For this reason the capacitance values cannot be directly related to desalination efficiency.

In the case of the ionic conductivity measured in the treated solution, the retention values obtained for the carbons under study are significantly lower than those obtained from the capacitance measurements (Table 2). Moreover, the removal efficiency observed for sample $A P$ is almost negligible and even lower than that obtained for $N P$, which clearly contradicts the results expected from their textural properties and their performance as a capacitor.

Several tests were performed in order to investigate the reasons for these unexpected results. It was found that the $\mathrm{pH}$ of the treated water, removed from the cell to measure the ionic conductivity, varied significantly. These changes were more significant for the cell with AP electrodes, in which the $\mathrm{pH}$ changed from the original value of $\approx 6$ to $\approx 3$ (Table 2). In the case of the electrodes prepared with carbon $N$, changes in $\mathrm{pH}$ were also observed but to a lesser extent (the $\mathrm{pH}$ increased up to $\approx 8$ ). These changes in $\mathrm{pH}$ can be attributed to chemical reactions involving the oxygenated functional groups present in the activated carbons [21] (see Supplementary data for additional details).

Independently of the phenomena that provoke these $\mathrm{pH}$ changes, the variations observed are relevant for the determination of the desalination efficiencies, as they imply changes in 
conductivity. This is clearly demonstrated by the results shown in Table 3 . The conductivities of $0.1 \mathrm{M} \mathrm{NaCl}$ standard solutions with different $\mathrm{pH}$ varied significantly, by as much as $4 \%$ variation in the molar concentrations calculated from these measurements. As a consequence, these $\sigma$ values are not suitable for accurately evaluating the desalination efficiency when $\mathrm{pH}$ changes occur.

The results discussed above make it clear that a new methodology is needed to monitor the desalinization process. We propose the direct measurement of chloride ions using a selective electrode. The results obtained for both carbons are shown in Table 2. $A$ and $N$, show a similar capability to remove salt from the solution. As explained above the amount of salt removed cannot be directly correlated with the textural properties, as the carbon pores are already filled with salt. The essential point is to demonstrate that direct determination of chloride ions is a reliable method and that it is independent of other factors such as $\mathrm{pH}$ variations.

\subsection{Validation of the methodology proposed}

As explained in the experimental section, the determination of the $\mathrm{Cl}^{-}$concentration using the incremental method does not require calibration, which simplifies the measurement procedure. In addition the detection limit depends on the sensitiveness of the electrode and the standard solution employed for the determination. An adequate selection of these two conditions would allow the method to be adapted to samples of different concentrations. The studies carried out with solutions of different concentrations (Table 4) show that this method is precise in concentration ranges relevant for desalination, with relative standard deviation values of 0.3-0.6 $\%$.

Once the precision of the CSE has been demonstrated, it is necessary to investigate whether the measurements are influenced by $\mathrm{pH}$. Table 5 shows the $\mathrm{NaCl}$ concentrations calculated from CSE measurements $\left.\left(\mathrm{X}_{\mathrm{NaCl}, \mathrm{Cl}}\right)^{-}\right)$of the $\mathrm{NaCl} 0.1 \mathrm{M}$ standard solution with different $\mathrm{pHs}$. The 
results obtained clearly demonstrate that the concentrations thus measured are not $\mathrm{pH}$ dependent.

\section{Conclusions}

It has been clearly evidenced that capacitance and ionic conductivity measurements are not always suitable for evaluating the efficiency of the desalination process. The changes in $\mathrm{pH}$ during the polarization of the CDI cell need to be evaluated and, when these changes occur, ionic conductivity cannot be used to assess the changes in salt concentration. The use of a chloride selective electrode to determine the salt concentration in CDI has been shown not only to be precise in a wide range of concentrations but also to be independent of $\mathrm{pH}$. In short this appears to be a simple and reliable alternative for monitoring the CDI process.

\section{Acknowledgements}

The authors thank MICINN and the European Union (project MAT2010-20601-C02-01) for the financial support provided. Patricia Díaz thanks MICINN for a FPI predoctoral research grant (FPI: BES-2011-045394).

\section{References}

[1] Gleick, P.H., Water in Crisis: A Guide to the World's Fresh Water Resources, Oxford University Press (1993) New York

[2] Simon, P., Tapped out: The Coming Worlds Crisis in Water we Can Do About It. Welcome Rain (1998) New York.

[3] Seo, S-J., Jeon, H., Lee, J.K., Kim, G-Y., Park, D., Nojima, H., Lee, J., Moon, S-H., Investigation on removal of hardness ions by capacitive deionization (CDI) for water softening applications. Water Research 44 (2010) 2267-2275. 
[4] Li, L., Zou, L., Song, H., Morris, G., Ordered mesoporous carbons synthesized by a modified sol-gel process for electrosorptive removal of sodium chloride. Carbon 47 (2003) 775-781.

[5] Zou, L., Morris, G., Qi, D., Using activated carbon electrode in electrosorptive deionisation of brackish water. Desalination 225 (2008) 329-340.

[6] Orem, Y., Capacitive deionization (CDI) for desalination and water treatment - past, present and future (a review). Desalination 228 (2008) 10-29.

[7] Hou, C-H., Huang, C-Y., A comparative study of electrosorption selectivity of ions by activated carbon electrodes in capacitive deionization. Desalination 314 (2013) 124-129.

[8] Xu. P., Drewes, J.E., Heil, D., Wang, G., Treatment of brackish produced water using carbon aerogel-based capacitive deionization technology. Water Research 42 (2008) 2605-2617.

[9] Yan, C., Zou, L., Short, R., Single-walled carbon nanotubes and polyaniline composites for capacitive deionization. Desalination 290 (2012) 125-129.

[10] Liang, P., Yuan, L., Yang, X., Zhou, S., Huang, X., Coupling ion-exchanges with inexpensive activated carbon fiber electrodes to enhance the performance of capacitive deionization cells for domestic wastewater desalination. Water Research 47 (2013) 2523-2530.

[11] Wang, H., Zhang, D., Yan, T., Wen, X., Shi, L., Zhang, J., Graphene prepared via a novel pyridine-thermal strategy for capacitive deionization. Journal of Material Chemistry 22 (2012) 23745-23748.

[12] Zhang, D., Wen, X., Shi, L., Yan, T., Zhang, J., Enhanced capacitive deionization of grapheme/mesoporous carbon composites. Nanoscale 4 (2012) 5440-5446.

[13] Zou, L., Li, L., Song, H., Morris, G., Using mesoporous carbon electrodes for brackish water desalination. Water Research 42 (2008) 2340-2348. 
[14] Choi, J-H., Fabrication of a carbon electrode using activated carbon powder and application to the capacitive deionization process. Separation and Purification Technology 70 (2010) 362-366.

[15] Nadakatti, S., Tendulkar, M., Kadam, M., Use of mesoporous conductive carbon black to enhance performance of activated carbon electrodes in capacitive deionization technology. Desalination 268 (2011) 182-188.

[16] Porada, S., Weinstein, L., Dash, R., van der Wal, A., Bryjak, M., Gogotsi, Y., Biesheuvel, P.M., Water Desalination Using Capacitive Deionization with Microporous Carbon Electrodes. Applied Materials \& Interfaces 4 (2012) 1194-1199.

[17] Ban, A., Schafer, A., Wendt, H., Fundamentals of electrosorption on activated carbon for wastewater treatment of industrial effluents. Journal of Applied Electrochemistry 28 (1998) 227-236.

[18] Lee, J-H., Bae, W-S., Choi, J-H., Electrode reactions and adsorption/desorption performance related to the applied potential in a capacitive deionization process. Desalination 258 (2010) 159-163

[19] Bouhadana, Y., Ben-Tzion, M., Soffer, A., Aurbach, D., A control system for operating and investigating reactors: the demonstration of parasitic reactions in the water desalination by capacitive de-ionization. Desalination 268 (2011) 253-261.

[20] Kim, T., Yoon, J., Relationship between capacitance of activated carbon composites electrodes at low electrolyte concentration and their desalination performance in capacitive deionization. Journal of Electroanalytical Chemistry 704 (2013) 169-174.

[21] Ruiz, V., Roldán, S., Villar, I., Blanco, C., Santamaría, R., Voltage dependence of carbon-based supercapacitors for pseudocapacitance quantification. Electrochimica Acta 95 (2013) 225-229.

[22] Mora, E., Ruiz, V., Santamaría, R., Blanco, C., Granda, M., Menéndez, R., JuarezGalán, J.M., Rodríguez-Reinoso, F., Influence of mesophase activation conditions on the specific capacitance of the resulting carbons. Journal of Power Sources 156 (2006) 719724. 
[23] Bitterlich, B., Lutz, C., Roosen, A., Rheological characterization of water-based slurries for the tape casting process. Ceramics International 28 (2002) 675-683.

[24] Suss, M.E., Baumann, T.F., Bourcier, W.L., Spadaccini, C.M., Rose, K.A., Santiago, J.G., Stadermann, M., Capacitive desalination with flow-through electrodes. Energy \& Environmental Science 5 (2012) 9511-9519.

[25] Porada, S., Zhao, R., van der Wal, A., Presser, V., Biesheuvel, P.M., Review on the science and technology of water desalination by capacitive deionization. Progress in Materials Science 58 (2013) 1388-1442.

[26] Conway, B. E., Electrochemical Capacitors: scientific fundamental and technological applications, Chapter 3, pp 53-54. Kluwer Academic, Plenum Publishers (1999) New York.

[27] Korytta, J., Theory and applications of ion-selective electrodes. Part II. Analytica Chimica Acta 91 (1977) 1-85.

[28] Florence, T.M., Differential potentiometric determination of parts per billion chloride with ion-selective electrodes. Journal of Electroanalytical Chemistry and Interfacial Electrochemistry 31 (1971) 77-86.

[29] Sekerka, I., Lechner, J.F., Wales, R., Determination of chloride in water with a $\mathrm{HgS} / \mathrm{Hg}_{2} \mathrm{Cl}_{2}$ electrode. Water Research 9 (1975) 663-665.

[30] Midgley, D., Gatford, D., Known addition-dilution titration potentiometry: a method for the determination of trace chloride in borax/nitrite solution. Microchemical Journal 42 (1990) 225-240.

[31] Moody, G. J., Thomas, J. D. R., Development and publication of work with selective ion-sensitive electrodes. Talanta 19 (1972) 623-639.

[32] Ruiz, V., Blanco, C., Granda, M., Menéndez, R., Santamaría, R., Influence of electrode preparation on the electrochemical behaviour of carbon-based supercapacitors. Journal of Applied Electrochemistry 37 (2007) 717-721. 
List of Tables

Table 1. - Characteristics of the activated carbons and electrode pastes.

\begin{tabular}{|cccccc|}
\hline Sample & $\begin{array}{c}\boldsymbol{V}_{\boldsymbol{t}} \\
\left(\mathbf{c m}^{\mathbf{3}} \mathbf{g}^{-\mathbf{1}}\right)\end{array}$ & $\begin{array}{c}\boldsymbol{V}_{\text {micro }} \\
\left(\mathbf{c m}^{\mathbf{3}} \mathbf{g}^{-\mathbf{1}}\right)\end{array}$ & $\begin{array}{c}\boldsymbol{S}_{\text {BET }} \\
\left(\mathbf{m}^{\mathbf{2}} \mathbf{g}^{\mathbf{- 1}}\right)\end{array}$ & $\begin{array}{c}\text { Smic } \\
\left(\mathbf{c m}^{\mathbf{3}} \mathbf{g}^{-\mathbf{1}}\right)\end{array}$ & $\begin{array}{c}\boldsymbol{O} \\
(\mathbf{w t} . \mathbf{\%})\end{array}$ \\
\hline $\boldsymbol{N}$ & 0.96 & 0.65 & 1749 & 966 & 2.83 \\
\hline $\boldsymbol{A}$ & 1.58 & 1.23 & 2966 & 1440 & 4.47 \\
\hline $\boldsymbol{N P}$ & 0.50 & 0.36 & 937 & 359 & - \\
\hline $\boldsymbol{A P}$ & 1.10 & 0.69 & 2181 & 743 & - \\
\hline
\end{tabular}

$V_{\mathrm{t}}=$ total pore volume; $V_{\text {micro }}=$ micropore volume; $S_{B E T} \equiv$ apparent specific surface area; $S_{\text {mic }}=$ microporous surface area; $O=$ oxygen content determined by elemental analysis

\begin{tabular}{|c|c|c|c|c|c|c|c|c|}
\hline Sample & Measurement & $\begin{array}{c}C \\
(F) \\
\end{array}$ & $\begin{array}{c}R_{C} \\
(m g / g) \\
\end{array}$ & $\begin{array}{c}\sigma \\
\left(m S \mathrm{~cm}^{-1}\right)\end{array}$ & $\begin{array}{c}\begin{array}{c}R_{\sigma} \\
(m g / g)\end{array} \\
\end{array}$ & $\begin{array}{c}\Delta E \\
(m V) \\
\end{array}$ & $\begin{array}{c}R_{C l}^{-} \\
(\mathrm{mg} / \mathrm{g})\end{array}$ & $p H^{*}$ \\
\hline \multirow{5}{*}{$N P$} & 1 & 9 & 21 & 10.38 & 5 & 14.6 & 9 & 8.05 \\
\hline & 2 & 9 & 21 & 10.41 & 4 & 14.7 & 8 & 7.70 \\
\hline & 3 & 9 & 21 & 10.40 & 4 & 14.8 & 8 & 6.57 \\
\hline & 4 & 9 & 21 & 10.48 & 3 & 14.8 & 7 & 6.97 \\
\hline & 5 & 9 & 21 & 10.35 & 5 & 14.8 & 7 & 6.17 \\
\hline \multirow{5}{*}{$\boldsymbol{A P}$} & 1 & 15 & 31 & 10.75 & 0 & 14.4 & 9 & 2.68 \\
\hline & 2 & 15 & 31 & 10.53 & 3 & 14.5 & 8 & 2.74 \\
\hline & 3 & 15 & 31 & 10.61 & 2 & 14.7 & 6 & 2.76 \\
\hline & 4 & 15 & 31 & 10.65 & 1 & 14.6 & 7 & 2.88 \\
\hline & 5 & 15 & 31 & 10.63 & 1 & 14.4 & 9 & 2.93 \\
\hline
\end{tabular}

$* \mathrm{pH}$ was measured in the desalinization experiments.

Table 3. - NaCl concentrations calculated from ionic conductivity measurements for $0.1 \mathrm{M} \mathrm{NaCl}$ solutions with different $\mathrm{pH}$.

\begin{tabular}{|c|c|c|}
\hline$p H$ & $\begin{array}{c}\sigma \\
\left(m S c m^{-1}\right)\end{array}$ & $\begin{array}{c}X_{N a C l, \sigma} \\
\left(\mathrm{mol} \mathrm{L}^{-1}\right)\end{array}$ \\
\hline 2.66 & 11.38 & 0.10557 \\
\hline 2.88 & 11.18 & 0.10353 \\
\hline 3.23 & 11.09 & 0.10262 \\
\hline 6.06 & 11.01 & 0.10180 \\
\hline 10.56 & 11.06 & 0.10231 \\
\hline
\end{tabular}




\section{Table 4. - Evaluation of the precision of the method}

\begin{tabular}{|cccc|}
\hline $\boldsymbol{X}_{\mathrm{NaCl}}\left(\mathbf{m o l ~ L}^{-\mathbf{1}}\right)$ & $\left.\boldsymbol{X}_{\mathrm{NaCl}, \mathrm{Cl}} \mathbf{( m o l ~ L}^{-\mathbf{1}}\right)$ & $\boldsymbol{e} \mathbf{( \% )}$ & $\boldsymbol{R S D} \mathbf{( \% )}$ \\
\hline $\mathbf{0 . 0 0 5 0}$ & 0.0048 & 4 & 0.5 \\
\hline $\mathbf{0 . 0 1 0 0}$ & 0.0099 & 1 & 0.3 \\
\hline $\mathbf{0 . 0 5 0 0}$ & 0.0485 & 3 & 0.4 \\
\hline $\mathbf{0 . 1 0 0 0}$ & 0.1005 & -0.5 & 0.5 \\
\hline $\mathbf{0 . 5 0 0 0}$ & 0.4998 & 0.04 & 0.6 \\
\hline
\end{tabular}

$X_{\mathrm{NaCl}}=\mathrm{NaCl}$ concentration of standard solutions; $X_{\mathrm{NaCl}, \mathrm{Cl}}{ }^{-}=\mathrm{NaCl}$ concentration determined by using a CSE and a sample addition method; $e(\%)=$ relative error; $R S D(\%)=$ relative standard deviation values .

\section{Table 5. - NaCl concentrations calculated from}

chloride ion concentration measurements for

$0.1 \mathrm{M} \mathrm{NaCl}$ solutions of different $\mathrm{pH}$.

\begin{tabular}{|ccc|}
\hline$p H$ & $\begin{array}{c}\boldsymbol{E} \boldsymbol{H} \\
(\boldsymbol{m} \boldsymbol{V})\end{array}$ & $\begin{array}{l}\boldsymbol{X}_{\mathrm{NaClCC}} \\
\left(\mathbf{m o l ~ L}^{-1}\right)\end{array}$ \\
\hline $\mathbf{2 . 6 6}$ & 15.1 & 0.09971 \\
\hline $\mathbf{2 . 8 8}$ & 15.1 & 0.09971 \\
\hline $\mathbf{3 . 2 3}$ & 15.1 & 0.09971 \\
\hline $\mathbf{6 . 0 6}$ & 15.1 & 0.09971 \\
\hline $\mathbf{1 0 . 5 6}$ & 15.0 & 0.09971 \\
\hline
\end{tabular}

\section{Figure Captions}

Fig. 1. - Scheme of the CDI process: A) polarization step and B) depolarization step.

Fig. 2.- Scheme of the CDI home-made device. 

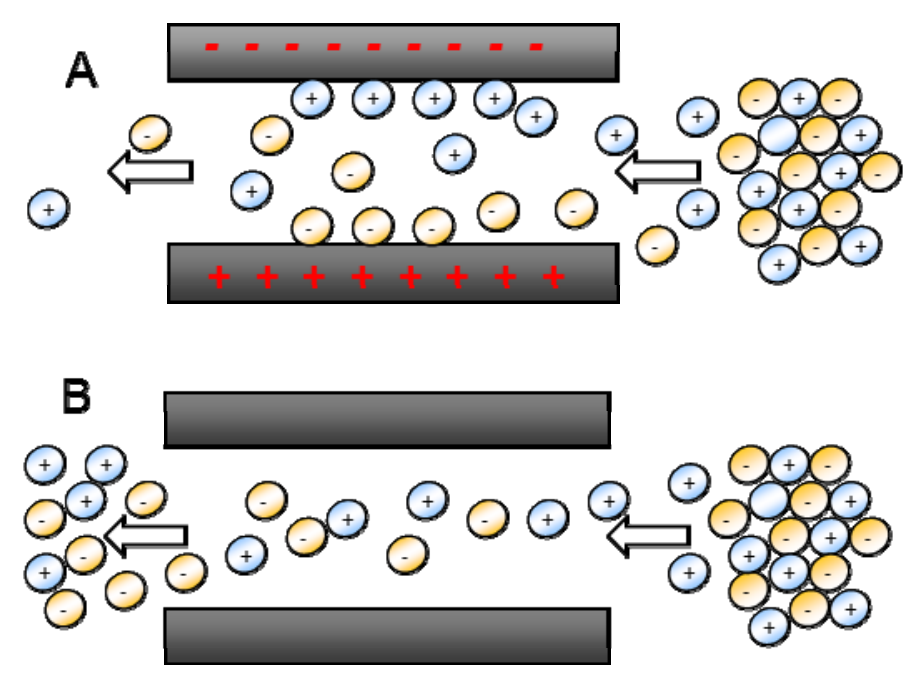

Figure 1

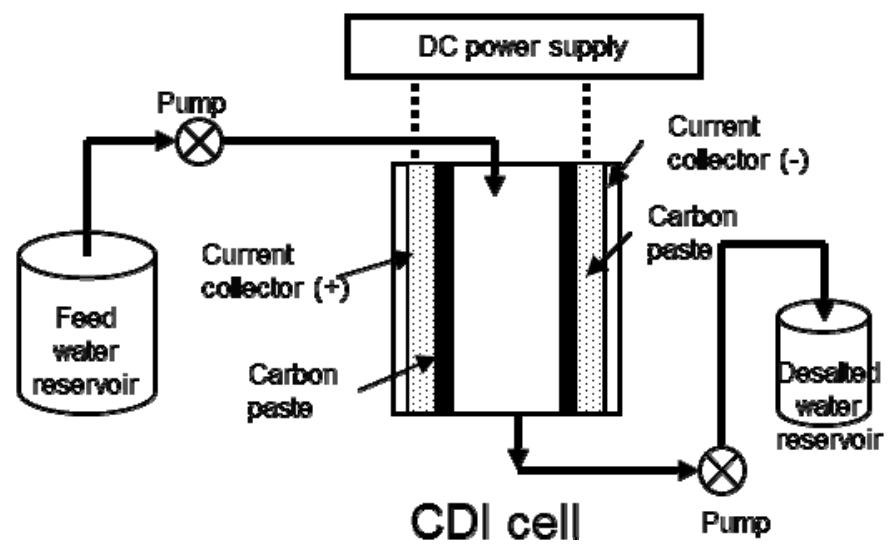

Figure 2 


\section{Supplementary Data}

\section{Capacitance values:}

Cell capacitance values $(C)$ and corresponding desalination efficiencies $\left(R_{c}\right)$ for both types of electrodes are shown in Table S1. For purposes of comparison with results summarized in the literature, Table $\mathrm{S} 1$ also shows electrode capacitance $\left(C_{e l}\right)$ expressed as specific electrode capacitance $\left(C_{s p, e l}\right)$. These values have been calculated from the discharge profiles of the GCPLs experiments by means of the following equation

$$
C_{s p, e l}(\mathrm{~F} / \mathrm{g})=2 I \Delta t / \Delta V m
$$

where $I$ is the discharge current (A), $\Delta t$ is the discharge time (s), $\Delta V$ is the voltage difference without the ohmic drop (V) and $m$ is the weight of the active electrode material (without any binder).

Table S2. - Specific electrode capacitance $\left(\boldsymbol{C}_{\text {sp.el }}\right)$ and experimental desalination efficiencies $\left(\boldsymbol{R}_{\text {exp }}\right)$ reported for different CDI electrode materials.

\begin{tabular}{|ccccc|}
\hline Sample & $\begin{array}{c}\boldsymbol{i} \\
\left(\boldsymbol{A} \cdot \boldsymbol{c m}^{-2}\right)\end{array}$ & $\begin{array}{c}\boldsymbol{C} \\
(\boldsymbol{F})\end{array}$ & $\begin{array}{c}\boldsymbol{C}_{\boldsymbol{s p}, \boldsymbol{e}, \boldsymbol{l}} \\
\left(\boldsymbol{F} \cdot \boldsymbol{g}^{-1}\right)\end{array}$ & $\begin{array}{c}\boldsymbol{R}_{\boldsymbol{c}} \\
\left(\boldsymbol{m g} \cdot \boldsymbol{g}^{-1}\right)\end{array}$ \\
\hline $\boldsymbol{N P}$ & 0.25 & 8.6 & 57 & 21 \\
$\boldsymbol{A P}$ & 0.25 & 14.5 & 85 & 31 \\
\hline
\end{tabular}




\section{Ionic conductivity measurements:}

Figure S1 show the ionic conductivity calibration curve, which can be adjusted to the equation:

$$
\sigma\left(\mathrm{mS} \mathrm{cm}^{-1}\right)=1.0129+98.202 X_{\mathrm{NaCl}}\left(\mathrm{mol} \mathrm{L}^{-1}\right)
$$

Linear range: $0.090-0.110 \mathrm{~mol} \mathrm{~L}^{-1}\left(5.264-6.464 \mathrm{~g} \mathrm{~mol}^{-1}\right)$

Precision and accuracy: $\pm 0.001 \mathrm{~mol} \mathrm{~L}^{-1}\left(0.0584 \mathrm{~g} \mathrm{~mol}^{-1}\right)$

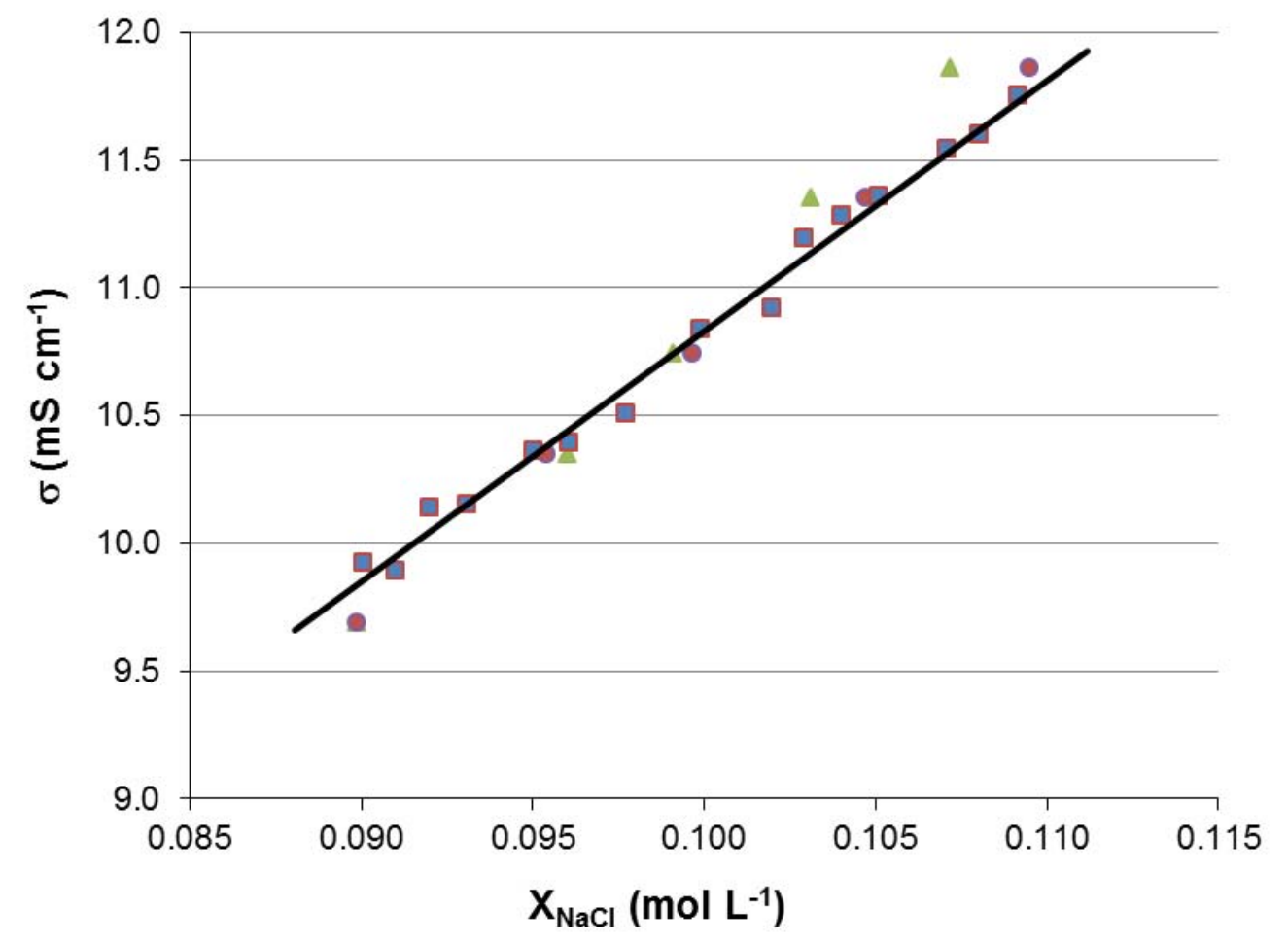

Figure S1. - Calibration curve of ionic conductivity values 
Determination of the chloride ions concentration by means of a CSE:

Figure $\mathrm{S} 2$ shows the relation between $\Delta E$ and $\mathrm{NaCl}$ concentration $\left(X_{\mathrm{NaCl}}\right)$ of the standard solutions determined for triplicate.

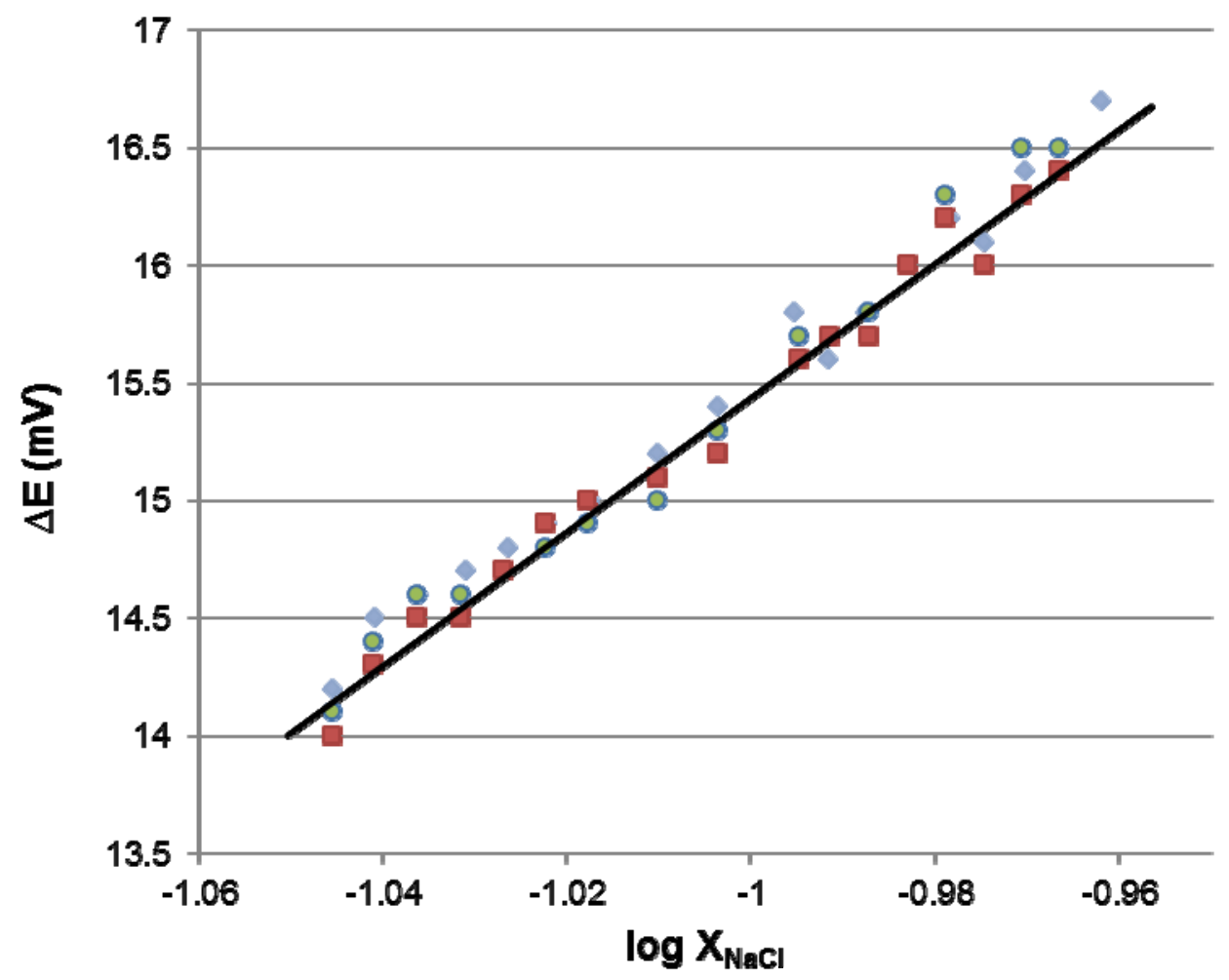

Figure S2. - Calibration curves for the determination of the chloride ions concentration using a CSE. 


\section{Experiments performed to study $\mathrm{pH}$ variations during desalination}

A salt solution with a $\mathrm{pH}$ of 5.5 was introduced in the desalinization cell and subjected to polarization-depolarization cycles of in the same conditions as those used in the desalination experiments but without removing water from the cell. The $\mathrm{pH}$ was measured after each polarization and depolarization step. Figure S3 shows the results obtained for each carbon electrode. The $\mathrm{pH}$ variations observed can be assigned to secondary reactions occurring on the electrodes. Nevertheless, the reversibility of the $\mathrm{pH}$ values observed in Figure S3 would be better explained by reversible reactions involving oxygenated functional groups on the surface of the carbon electrodes. Such reactions are commonly observed in these systems and are responsible for pseudocapacitance.

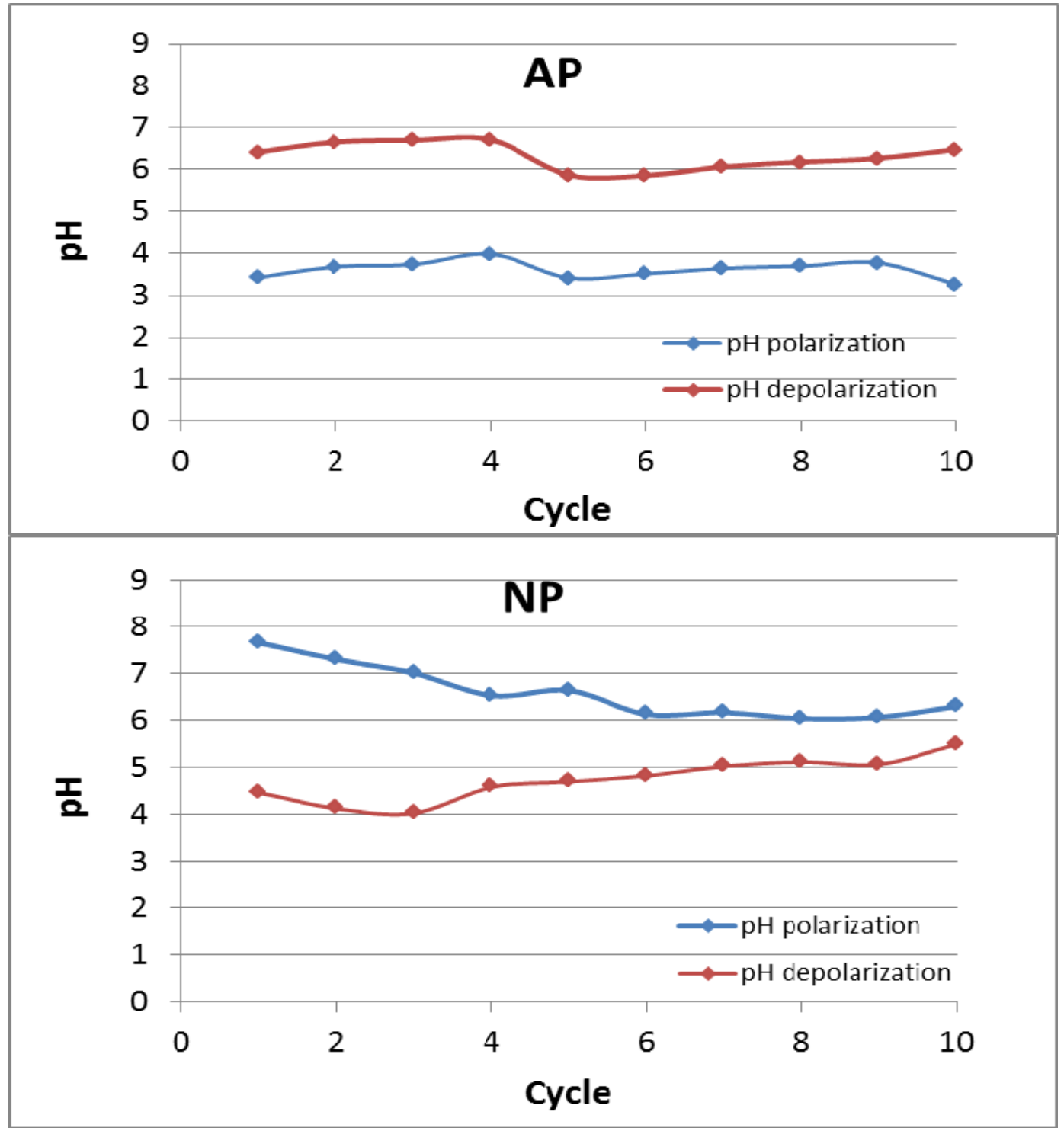

Figure S3.- $\mathrm{pH}$ variations measurement during desalination experiments. 